\title{
Uhl's Anomaly. Differential Diagnosis and Indication for Cardiac Transplantation in an Infant
}

\author{
Nana Miura Ikari, Estela Azeka, Vera Demarchi Aiello, Edmar Atik, Miguel Barbero-Marcial, Munir Ebaid \\ São Paulo, SP - Brazil
}

We report the case of an 8-month-old female infant with Uhl's anomaly, who underwent successful cardiac transplantation. The clinical findings, complementary laboratory tests, anatomic findings, and differential diagnosis of the anomaly are discussed.

In the past, the diagnosis of Uhl's anomaly was usually made on autopsy. Currently, the development of graphic and imaging methods have made an early and more accurate clinical diagnosis possible, even though controversies about its etiopathogeny still remain. We report the case of a female infant with Uhl's anomaly, who underwent successful cardiac transplantation, with special emphasis on the clinical findings and complementary laboratory tests, such as chest X-ray, electrocardiography, echocardiography, magnetic resonance imaging, hemodynamic study, and anatomicopathological study of the heart.

\section{Case report}

The patient was an 8-month-old female infant with a history of deficient weight and height since the age of 3 months, and congestive heart failure since the age of 6 months.

On physical examination, the infant was in good general condition, slightly tachypneic, acyanotic, and her pulses were present and symmetric. In the precordia, systolic impulsions were visible in the lower left sternal margin. On cardiac auscultation, a mild systolic murmur could be heard in the lower left sternal margin. There was a moderate hepatomegaly.

On chest X-ray (fig. 1), a marked cardiomegaly with a slight increase in the pulmonary vascular net could be seen. Electrocardiography showed right atrial and ventricular hypertrophy (fig. 2).

Instituto do Coração do Hospital das Clínicas - FMUSP

Mailing address: Nana Miura Ikari - InCor - Av. Dr. Enéas C. Aguiar, 44 - 05403-000

- São Paulo, SP, Brazil - e-mail: nikari@ cardiol.br

English version by Stela Maris C. e Gandour
Doppler echocardiography showed an important tricuspid insufficiency, marked dilation of the right ventricle with diffuse hypokinesia, presence of a discrete pericardial effusion, and thrombus on the anterior wall of the right ventricular inlet. Left ventricular shortening fraction was $36 \%$.

The radionuclide angioventriculography revealed left and right ventricular ejection fractions of $35 \%$ and $20 \%$, respectively.

On cardiac catheterization, the presence of marked dilation of the right atrium and ventricle was confirmed, as were an important tricuspid insufficiency and a thrombus in the right ventricle. Manometry showed a mean pressure of $14 \mathrm{mmHg}$ in the right atrium, and pressure of $20 / 14 \mathrm{mmHg}$ in the right ventricle and pulmonary trunk (fig. 3).

Magnetic resonance imaging showed, in addition to the marked enlargement of the right atrium, a clear reduction in thickness of the right ventricular wall.

Despite intensive treatment, no clinical improvement was observed. The patient underwent orthotopic cardiac transplantation at the age of 11 months and was evolving clinically well 6 months after the procedure.

Anatomicopathological study - The cardiac segment analyzed comprised the ventricles and most of the right atrium, in addition to the proximal segments of the pulmonary trunk and ascending aorta. The tricuspid valve was inserted in its habitual position with no fusion of the cusps, but with a moderate dilation of the valvar ring. Their cords were thin and delicate. The right ventricle was dilated, and its walls had a whitish color and were extremely thin (fig. 4). The cross-sections showed an almost complete replacement of the myocardium of the free wall of the right ventricle by a whitish tissue, which sparred the ventricular septum, a few trabeculae, and the papillary muscles (fig. 5). A mural thrombus of $0.8 \mathrm{~cm}$ of diameter was noted, adhered to the endocardium of the diaphragmatic wall in the right ventricular inlet. The left ventricle had a preserved thickness and slight dilation of its cavity. The histological sections showed extensive bands of right ventricular wall constituted by fibrous connective tissue, with the endocardium at one side and epicardium at the other. Foci of inflammatory 


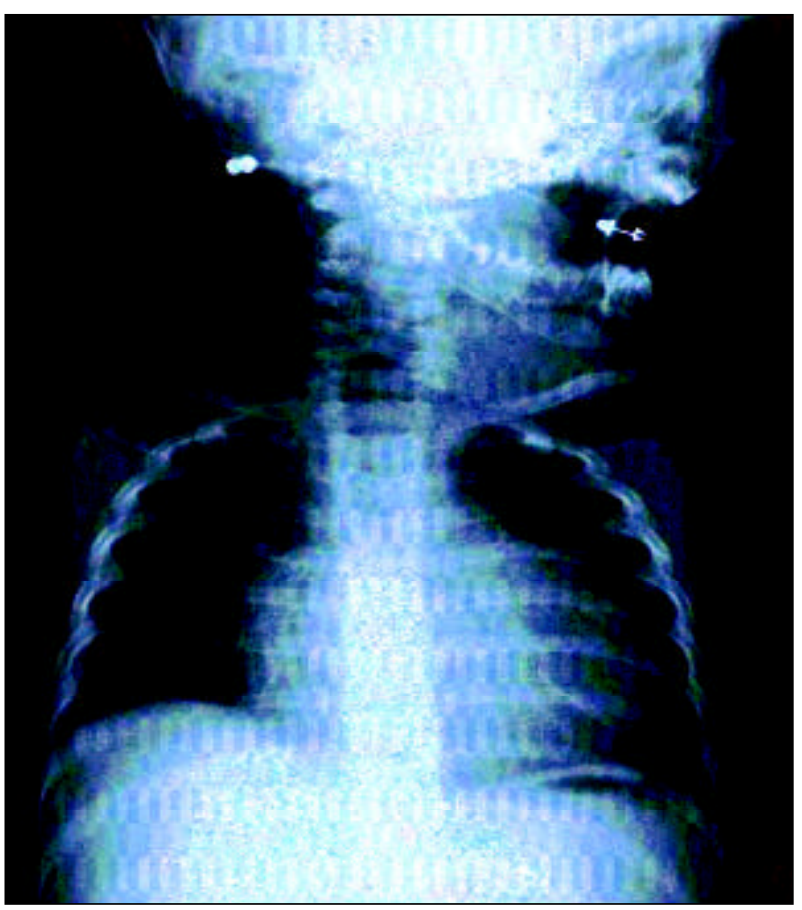

Fig. 1 - Chest X-ray showing marked cardiomegaly

lymphocytic and plasma cells were observed close to the epicardium. In other regions, myocardial fibers remained intermingled with variable amounts of fibrous tissue.

\section{Discussion}

In 1905 , Osler ${ }^{1}$ was the first to report a heart with a very thin wall similar to parchment. In 1949, $\mathrm{Uhl}^{2}$ reported his first case after performing an autopsy on an 8-month-old infant. Coincidentally, in 1952, 2 articles were published; one was
Uhl's case of the 8-month-old infant ${ }^{2}$, and the other was a study by Castleman and Towne ${ }^{3}$ in an adult, reporting alterations in the right ventricle, such as myocardial loss resulting in thin walls with rare muscle fibers. Both cases had no antecedents of inflammatory processes, such as myocarditis or obstructive lesions in the coronary arteries, which could explain the myocardial destruction.

Uhl's anomaly has been reported in the international medical literature under this eponym either in its isolated form or in association with other heart diseases. Other names have also been used, such as right ventricular ectasia, congenital right ventricular myocardial aplasia, fat infiltration or lipomatosis, right ventricular idiopathic myocardial dysplasia, and right ventricular myocardial absence.

In 1979, Fontaine et al. ${ }^{4}$ reported another entity with a higher incidence, right ventricular arrhythmogenic dysplasia, whose lesion is characterized by local deficiency of the ventricular myocardium, which is replaced by fibrous and adipose tissues.

Recent studies of Uhl's anomaly ${ }^{5}$ have shown that it is a different disease from right ventricular arrhythmogenic dysplasia, with distinct morphological and clinical features, such as familial history, sex, age, clinical presentation, exercise-induced death, associated anomalies, morphological features, etiology, and pathogenesis.

In our case, the infant had no familial antecedents of Uhl's anomaly, which may happen in right ventricular arrhythmogenic dysplasia. In regard to sex, the male sex predominates with an incidence of $56 \%$ in Uhl's anomaly and $70 \%$ in the arrhythmogenic dysplasia.

The major clinical finding in Uhl's anomaly is heart failure, as happened with our infant. Complaints like palpitation, syncope, ventricular tachycardia, and sudden death, many times induced by physical exercise, are more frequen-

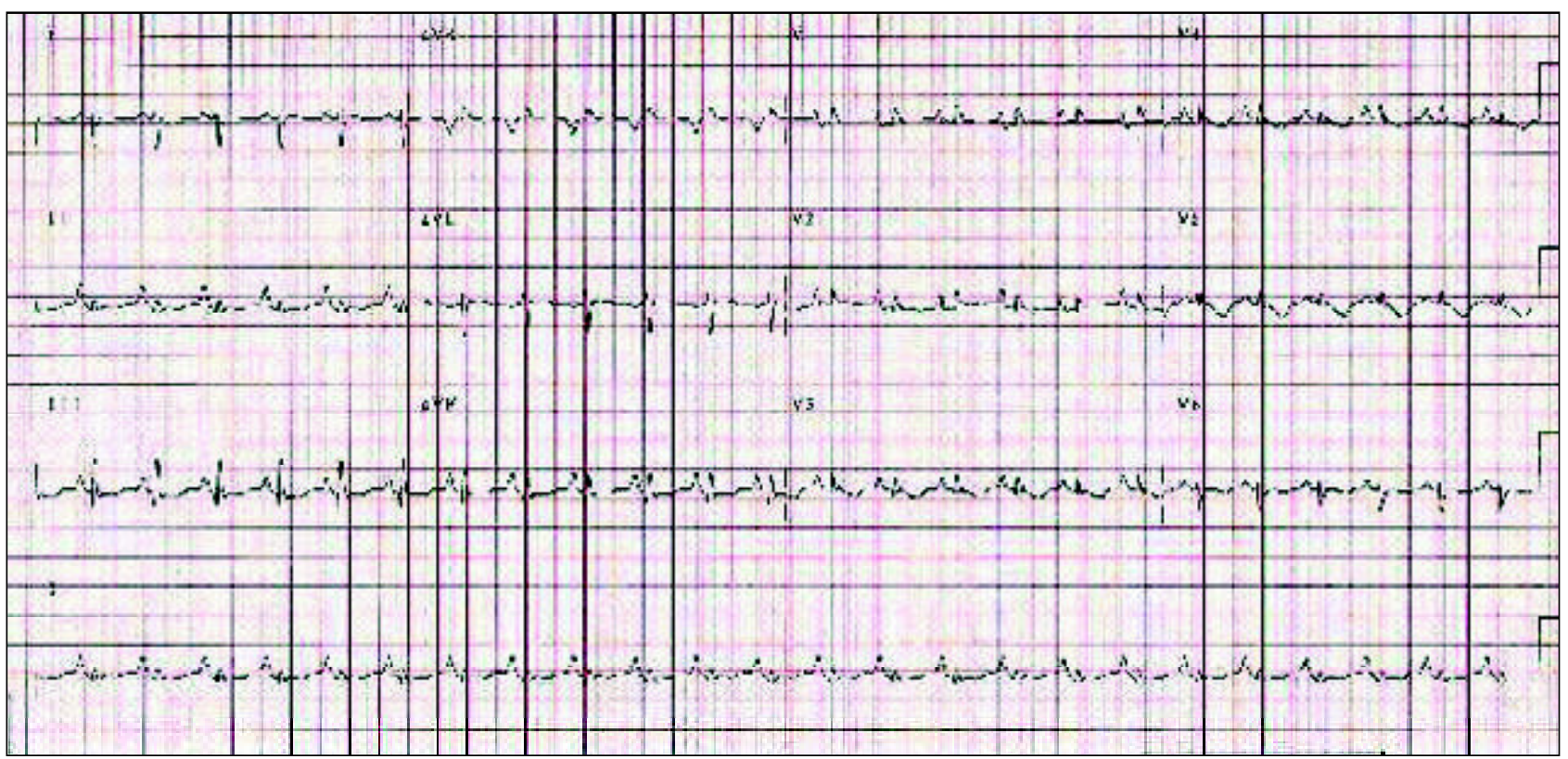

Fig. 2 - Electrocardiography showing hypertrophy of the right chambers. 

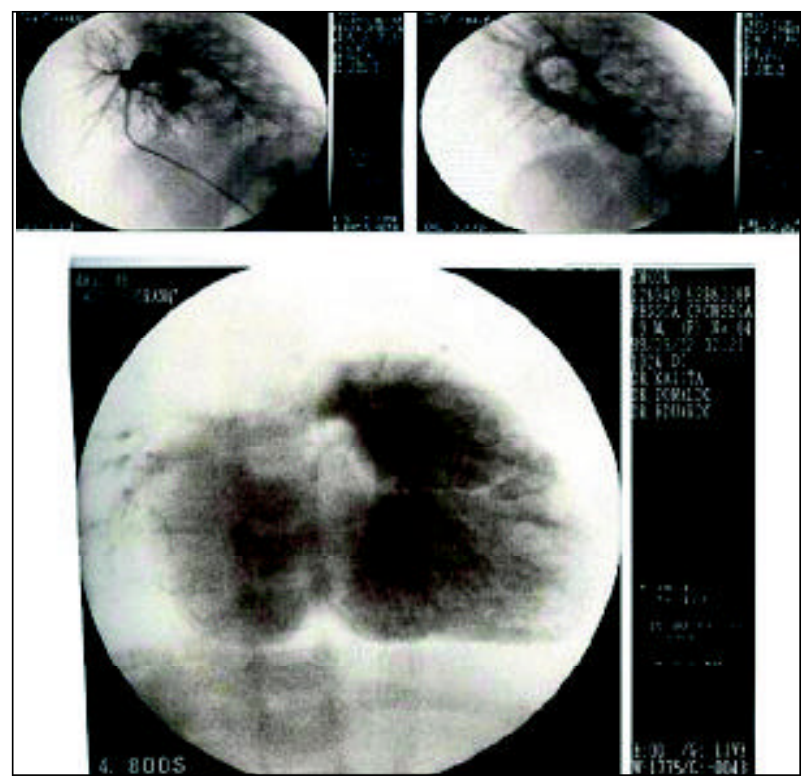

Fig. 3 - Right cardiac catheterization with atriography and ventriculography showing marked dilation of the chambers and tricuspid regurgitation.

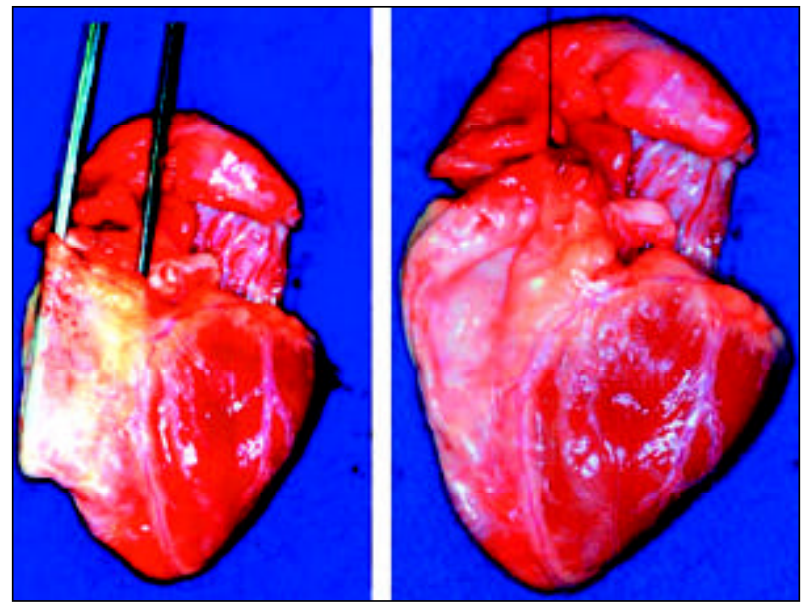

Fig. 4 - Gross appearance of the heart showing a dilated right ventricle with thin walls.

tly related to arrhythmogenic dysplasia ${ }^{6,7}$. In our patient, Uhl's anomaly manifested as refractory congestive heart failure with a thrombus in the right ventricular inlet, culminating in the indication for orthotopic cardiac transplantation, which, at our institution (InCor) has an actuarial survival of $90 \%$ in 1 year and $78.2 \%$ in 6 years ${ }^{8}$.

In the review by Gerlis et al. ${ }^{9}$, the authors concluded that the name "Uhl's anomaly" had been given to many cases that would be currently described as right ventricular arrhythmogenic dysplasia. Uhl's anomaly has morphological features, such as complete absence of myocardium in the right ventricular parietal wall, which is composed only by surfaces of endocardium and epicardium with no interposition of adipose tissue between these layers, as observed in our patient's heart. On the other hand, in arrhythmogenic dysplasia, fibrous and adipose tissues replace the myocardium of the right ventricular wall.

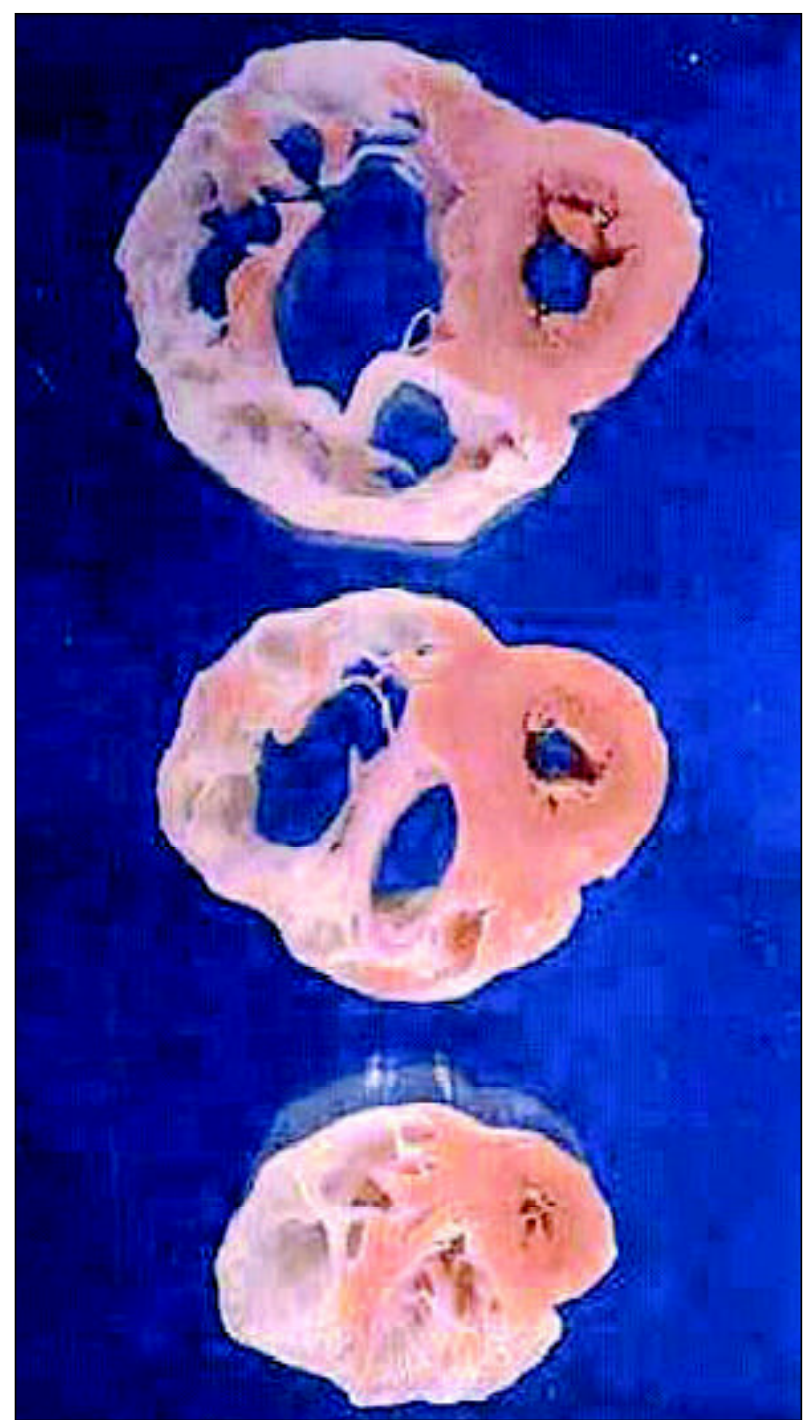

Fig. 5 - Gross transections of the heart showing dilated right ventricle with thin walls and fibrous replacement of the myocardium. The ventricular septum and left ventricle are preserved.

Despite several reports, a reasonable explanation for the absence of myocardium in the right ventricle is still lacking. A failure in development during embryonic life is a possible cause. According to Uhl, a failure during embryonic development of the right ventricular myocardium occurs, and according to Dalla Volta ${ }^{10}$, a greater sensitivity of the right ventricle exposed to aggressions during intrauterine life occurs due to an increase in pressure and resistance higher than those in the left ventricle. Recently, the hypothesis that the right ventricular myocardium may be replaced due to a process of apoptosis of the myocardiocytes has been cogitated and supported by studies of molecular biology ${ }^{11}$.

The histological aspect observed in our patient's heart sections allows the hypothesis of the occurrence of a previous inflammatory process in the myocardium, with partial fibrous replacement of the wall. Several points, 
however, still require clarification, such as the exclusive involvement of the right ventricle and the existence of a possible etiologic agent in the process.

In regard to the similarity of Uhl's anomaly with right ventricular arrhythmogenic dysplasia, the hypothesis that both entities (even though distinctive from the morphological point of view) may have the same etiopathogenesis is reasonable to be considered, even though they occur at different times in life.

\section{Acknowledgements}

We thank Dr. Maria Aparecida Bhering, for her valuable suggestions concerning the patient.

\section{References}

1. Osler WM. The principles and practice of medicine. $6^{\text {th }}$ ed. New York: D. Appleton, 1905: 280.

2. Uhl HSM. A previously underscrib congenital malformation of the heart: almost total absence of the myocardium of the rigth ventricle. Bulletin of the Johns Hopkins Hospital 1952; 91: 197-209.

3. Castleman B, Towne VW. Presentation of case 38201. N Engl J Med 1952; 246: 785-90.

4. Fontaine G, Guiraudon G, Frank R. Mechanism of ventricular tachycardia with and without associated chronic myocardial ischemia: surgical management based on epicardial mapping. In: Narula OS, ed. Cardiac Arrhythmias. Baltimore and London: Williams and Wilkins, 1979: 516-23.

5. Uhl HS. Uhl's anomaly revisited. Circulation 1996; 93: 1483-4.
6. Loire R, Tabib A. Arrhythmogenic right ventricular dysplasia and Uhl disease. Anatomic study of 100 cases after sudden death. Ann Pathol 1998; 18: 165-71.

7. Loire R, Tabib A. Unexpected sudden cardiac death. An evaluation of 1000 autopsies. Arch Mal Coeur Vaiss 1996; 89: 13-8.

8. Azeka E, Barbero-Marcial M, Jatene M, et al. Transplante cardíaco no neonato e na infância. Resultados a médio prazo. Arq Bras Cardiol 2000; 74: 197-202.

9. Gerlis LM, Schmidt-Ott SC, Ho SY, Anderson RH. Dysplastic conditions of the right ventricular myocardium: Uhl's anomaly vs arrhythmogenic right ventricular dysplasia. Br Heart J 1993; 69: 142-50.

10. Dalla Volta S. Arrythmogenic cardiomyopathy of the right ventricle: thoughts of aetiology. Eur Heart J 1989; 10(suppl D): 2-6.

11. James TN, Nicholas MM, Sapire DW, Patre PL, Lopez SM. Complete heart block and fatal right ventricular failure in an infant. Circulation 1996; 93: 1588-600. 